\title{
Entre o precário e o (in)sustentável: discursos de sustentabilidade em projetos habitacionais do Programa de Aceleração do Crescimento em Belém (PA)
}

\section{Between the precarious and the (un)sustainable: sustainability discourses in housing projects of the Growth Acceleration Program in Belém (PA)}

\author{
Marlon D’Oliveira Castro ${ }^{1}$
}

\begin{abstract}
RESUMO
Este artigo discute a presença de discursos de sustentabilidade na produção do espaço urbano promovida pelo Programa de Aceleração do Crescimento (PAC), na sua linha Urbanização de Assentamentos Precários (UAP), para remoção urbana de famílias em situação de risco socioambiental (reassentamento e remanejamento). A partir de metodologia qualitativa apoiada no materialismo histórico-dialético, foi realizado estudo de caso sobre intervenção do PAC, a partir de seu PTTS, de projetos de habitação voltados à remoção de famílias ocupantes de espaços vulneráveis ambiental e socialmente, em Belém (PA): a Comunidade Taboquinha, no Distrito de Icoaraci. A análise exprimiu, a partir do olhar de agentes envolvidos e da trajetória dos sujeitos na transição entre espaços e seu cotidiano, o distanciamento entre a efetivação da política e a sustentabilidade nas perspectivas ambiental, social e econômica, pretendidas no bojo do Programa, demonstrando que não é possível pensar nos conjuntos habitacionais periféricos para remoção de famílias em vulnerabilidade ambiental, descolados da realidade e do sistema econômico que o produz, além das implicações que essa produção traz consigo para o espaço e a sociedade.
\end{abstract}

Palavras-chave: Discursos de sustentabilidade; Programa de Aceleração do Crescimento; (In)sustentabilidade.

\section{ABSTRACT}

This article discusses the presence of sustainability discourses in the production of urban space promoted by the Growth Acceleration Program (PAC), in its Urbanization of Precarious Settlements (UAP) line, for the urban removal of families at socio-environmental risk (resettlement and relocation). Based on a qualitative methodology supported by historical-dialectical materialism, a case study was carried out on the intervention of the PAC, based on its PTTS, of housing projects aimed at the removal of families living in environmentally and socially vulnerable spaces, in Belém (PA): the Taboquinha Community, in the District of Icoaraci. The analysis expressed, from the perspective of agents involved and the trajectory of the subjects in the transition between spaces and their daily lives, the gap between the implementation of the policy and sustainability in the environmental, social and economic perspectives, intended in the heart of the Program, demonstrating that it is not possible to think of peripheral housing projects for the removal of families in environmental vulnerability, detached from reality and the economic system that produces it, in addition to the implications that this production brings with it for space and society.

Keywords: Sustainability discourses; Growth Acceleration Program; (Un)sustainability.

\footnotetext{
${ }^{1}$ Universidade Federal do Pará - marloncastro@ufpa.br
} 


\section{INTRODUÇÃO}

As leituras sobre sustentabilidade são, muitas vezes, controversas, quando não, dúbias ou vazias de significado. Ora as cidades são vistas como objetos passíveis de tecnificação e, com isso, passam a ter diminuídos os seus gastos de energia e fluxos; ora são vistas simplesmente como zonas de reprodução social do capital e suas estruturas, sem nexo direto com a efetivação do bem estar humano.

O conceito de desenvolvimento sustentável no espaço urbano viria, desse modo, compatibilizar essas relações, mas, que, da forma colocada nas últimas três décadas, principalmente, consolidou-se diretamente atrelado a uma forma hegemônica de pensar a sociedade e a natureza, ignorando as determinações históricas do processo produtivo capitalista permanecendo radicado muito mais como uma ideologia que unifica os interesses dos trabalhadores, dos empresários e do Estado em torno da defesa de uma pretensa sustentabilidade ambiental, social e econômica.

Aplicado à produção do espaço urbano, o conceito de sustentabilidade tem sido aprofundado tanto no viés da cidade como representação tecno-material e eficiência ecoenergética, quanto no seu entendimento como espaço da qualidade de vida e lócus da legitimação de políticas públicas (ACSELRAD, 2009). Entretanto, a dimensão humana do conceito comumente tem ficado à margem das análises, que se pautam principalmente em elementos físicos e indicadores socioeconômicos. Em relação às políticas habitacionais, vê-se que o elemento sustentabilidade é muito propalado, inclusive, existindo certificações e projetos de trabalho técnico-sociais que ratificariam, nas intervenções, a garantia de sustentabilidade desde o projeto até o pós-ocupação, o que, entretanto, não dá garantias por si, da consolidação da conexão entre a intervenção, as necessidades da população atendida e a cidade.

Este artigo tem como objetivos: a) identificar as dimensões da questão ambiental na ótica de importantes autores a partir de estudos que relacionam as temáticas ambiental e urbana, percorrendo a trajetória da noção de sustentabilidade e as cidades; e b) analisar a presença discursiva das noções de sustentabilidade na produção habitacional do Programa de Aceleração do Crescimento (PAC), em Belém, PA. Para tanto, é abordada a produção do espaço intraurbano por meio de intervenções habitacionais de interesse social, destinadas à remoção e ao remanejamento de famílias de áreas vulneráveis social e ambientalmente em Belém, Pará, elaboradas e executadas em parceria entre o estado e prefeitura com o Governo Federal, via Programa de Aceleração do Crescimento (PAC). 
A partir de metodologia qualitativa apoiada no materialismo histórico-dialético, foi realizado um estudo de caso sobre intervenções do PAC, a partir de seu PTTS, de projetos de habitação voltados à remoção de famílias ocupantes de espaços vulneráveis ambiental e socialmente em Belém: a Comunidade Taboquinha (Conjuntos Verequete, Mestre Cardoso e Cruzeiro), no Distrito de Icoaraci, em Belém.

O artigo evidencia as contradições na implementação da política de habitação no processo para reassentamento das famílias, surgimento de outros problemas ligados à inserção na malha urbana, o que denota o distanciamento daquilo que poderia ser chamado de sustentabilidade urbana ou num espaço produzido que ratifique a cidade como lugar de legitimação das políticas urbanas (ACSELRAD, 2009); sem incorporar lutas sociais das comunidades envolvidas (LEFF, 2009); ou sem coadunar com o pressuposto da cidade como espaço de interação e ratificação de sua função social (SOUZA, 2009).

\section{As cidades e a sustentabilidade}

Entre outras definições, as cidades podem ser compreendidas como lócus de construção social, que se afirmam como espaço de trocas e do encontro, a partir de relações sociais que são impressas em um determinado tempo e espaço, isto é, obras, locais de criação e de relacionamento, onde se estabelecem as centralidades, como frisam Lefebvre (2001) e Gottdiener (2010). Dentre as relações mais frequentes estão: as econômicas, culturais, sociais e humanas, que dão características específicas a esse ambiente construído.

Segundo Souza (2009) a cidade pode ser compreendida como espaço de interação e que necessariamente precisa estar pautada em uma função social,

um local de aglomeração humana onde as pessoas desempenham atividades das mais diversas, agindo e interagindo entre si, buscando, na medida do possível, uma melhoria em suas qualidades de vida, pressupondo estas, necessariamente, estudos técnicos voltados a tornar eficaz a função social da cidade, procurando compatibilizar os problemas apresentados pela urbe e os anseios de seus habitantes (SOUZA, 2009, p. 59).

O autor defende dois dos vários pontos cruciais na questão das contradições da cidade: melhoria da qualidade de vida e função social. Vista sob este prisma, a cidade teria necessariamente de ser entendida como lugar de viabilidade da vida, de materialização do bem estar e consequentemente de exercício da cidadania. 
Entretanto, analisar as contradições espaciais da cidade e do urbano apenas ganha concretude se estas estiverem relacionadas ao entendimento do modo de produção vigente e do nível de comprometimento das cidades na reprodução social de um modelo econômico, social e político considerado insustentável. Por este ângulo, a conformação do design espacial urbano, descrito por Lefebvbre (2001) como produto das relações sociais concretas e suas contradições, ganha especial sentido, principalmente a partir da emergência do regime de acumulação flexível, onde a sustentabilidade é tida como especial característica de novo modo de regulação urbana. (ACSELRAD 2009; GOTTDIENER, 2010).

Do conflito entre viver e crescer suscitou-se que as cidades precisavam se tornar “cidades sustentáveis" em função da reestruturação pela qual o sistema econômico mundial passou nas últimas décadas. No modelo de desenvolvimento urbano sustentável, as questões ambientais foram incorporadas e podem até ser discutidas, desde que não comprometam o desenvolvimento urbano.

Prado (2015) diz que o desenvolvimento urbano sustentável não só é uma contradição de termos pelos conflitos inerentes à tentativa de fazer convergir os olhares do campo das análises e planejamento urbano com aqueles oriundos das disciplinas ambientais, mas principalmente, pelas contradições que a própria ideia de "sustentabilidade" contém e que são evidenciadas no território urbano. De forma que " $A$ aplicação da ideia de "desenvolvimento sustentável" aos discursos e práticas ligados ao fenômeno urbano, na forma de "desenvolvimento urbano sustentável", ampliou as limitações e contradições que o termo original trazia”. (PRADO, 2015, p.92).

A transposição da noção de sustentabilidade não se dá de forma confortável para o urbano. Assenta-se principalmente na crítica sobre os rumos do urbanismo em tempos de acumulação flexível, estando condicionada à lógica das práticas espaciais resultantes do modelo desigual de cidades baseado na diferenciação dos espaços intraurbanos e desigualdade social. Características como habitação precária em áreas inundáveis e de risco, em áreas de alta vulnerabilidade ambiental e também social, problemas de mobilidade e infraestrutura urbana, insegurança e violência, precariedade no acesso à água potável, diminuição da quantidade e qualidade de espaços públicos, etc., reforçam a compreensão de que a existência desta materialidade se dá conjugada à existência de outros espaços totalmente dotados de infraestrutura, atendendo a uma menor parcela privilegiada da sociedade (ACSELRAD, 2009). 
No entanto, percebe-se claramente que a discussão não está posta sobre a origem dos problemas - a desigualdade social - mas sobre suas consequências mais visíveis. $O$ contexto de globalização econômica tem aprofundado problemas historicamente presentes nas cidades que concentram acentuada desigualdade social, sobretudo nos países considerados "em desenvolvimento", como o Brasil, que possuem cidades com uma gama de problemas que não são apenas ambientais, mas fundamentalmente sociais.

Desta maneira, a noção de sustentabilidade encontra-se submetida à racionalidade de produção do espaço de forma pragmática, flexível e baseada na desigualdade. Sua aplicabilidade está condicionada não apenas à questão semântica, mas pelo pragmatismo que possa torná-la evidente como elemento agregador de valor social e de respeitabilidade teórica. O conceito ou os conceitos de sustentabilidade estão postos ora de forma discursiva, ora de forma pragmática. Sustentabilidade tornou-se slogan de partidos políticos, de empresas, de supermercados, de indústrias de veículos, etc., na tentativa de criar um ambiente de familiaridade entre sujeitos e a noção, que serviria muito mais ao marketing e ao sucesso empresarial que propriamente à redução de impactos ambientalmente negativos e mudanças na produção.

A sustentabilidade urbana prática é, assim, o esforço para tornar a cidade atraente para o capital, tornando-a mais funcional, conservando matéria, informação e energia, fazendo com que a acumulação urbana flua. A sustentabilidade urbana retórica ou discursiva, por outro lado, propõe um meio de neutralizar a crítica ambientalista pela introdução da variável ambiental nas políticas públicas e no planejamento, necessária a possibilitar legitimidade aos planejadores e, em última análise, contribuir para tornar a cidade mais competitiva (ACSELRAD, 2009).

Para Acselrad, há três representações distintas de cidade, às quais responderão também ao aspecto da valoração da sustentabilidade urbana: a Representação tecnomaterial das cidades; Cidade como espaço de qualidade de vida; e, Cidade como espaço de legitimação das políticas públicas urbanas.

Na Representação tecno-material das cidades, há uma tentativa de articulação entre a base produtiva e modelos de ecoeficiência energética ou "metabolismo urbano". Nas duas situações a cidade é vista a partir do controle de seus estoques e fluxos, principalmente de energia. Na tentativa de reduzir os impactos entrópicos, isto é, de dentro do próprio sistema, causados pelas práticas urbanas, a alternativa proposta é adoção de tecnologias limpas, isto é, que economizem espaço, matéria e energia, visando 
adaptar a produção e a vida urbanas através da densificação técnica e humana, sendo, portanto, um arranjo dentro da racionalidade econômica.

A sustentabilidade, neste caso, resultaria da redistribuição da pressão técnica de populações e recursos sobre a base de recursos ambientais urbanos, pois haveria a "hipótese do limite da capacidade urbana". No discurso, é dada ênfase a estratégias argumentativas de ordem global ganharão força como introdução de tecnologias urbanas poupadoras de recursos, reciclagem, redistribuição espacial de populações e atividades, redução do consumo per capita, entre outros. A busca por ecoeficiência seria causada por razões do próprio "urbano" e não por razões de ordem planetária, assim a ecoeficiência é legitimada como eixo das estratégias de ação e o mercado seu melhor instrumento (ACSELRAD, 1999).

A Cidade como espaço de qualidade de vida seria uma reposta do urbano ao modelo de desenvolvimento das cidades, principalmente ao consumo. A artificialidade do urbano crescentemente impregnaria os habitantes das cidades com substâncias nocivas e tóxicas, como imposição do modelo de reprodução para os centros urbanos. As emissões líquidas e gasosas resultantes das tecnologias urbanas são entendidas como imposição de consumo forçado de produtos que pela sua artificialidade, comprometeriam a qualidade de vida na cidade.

Para Acselrad, a noção de sustentabilidade urbana pode também articular as estratégias argumentativas da eficiência ecoenergética, da autossuficiência e da qualidade de vida na consideração da forma urbana como "fator determinante da sustentabilidade". A noção de "cidade compacta" reuniria os atributos de "alta densidade e uso misto, tendendo a apresentar superior eficiência energética por reduzir as distâncias dos trajetos, maximizar a oferta de transporte público e prover qualidade de vida superior aos residentes". No caso da sustentabilidade do desenvolvimento em geral, o argumento da autossuficiência remete a uma crítica do livre mercado e da globalização; no caso da autossuficiência urbana, trata-se de, em nome do combate ao efeito estufa e aos processos entrópicos, orientar-se para maior autonomia energética e econômica das localidades.

A Cidade como espaço de legitimação das políticas públicas urbanas compreende que sendo a materialidade das cidades politicamente construída, as modalidades de sua reprodução são vistas por Acselrad como dependentes das condições que legitimam seus pressupostos políticos. A ideia de sustentabilidade é, nesta representação, aplicada às condições de reprodução da legitimidade das políticas urbanas. Fala-se da viabilidade 
política do crescimento urbano, ou seja, das condições de construção política da base material das cidades.

A (in)sustentabilidade exprimiria, assim, a incapacidade das políticas urbanas adaptarem a oferta de serviços urbanos à quantidade e qualidade das demandas sociais, provocando um "desequilíbrio entre necessidades quotidianas da população e os meios de as satisfazer, entre a demanda por serviços urbanos $e$ os investimentos em redes $e$ infraestrutura". A insustentabilidade estaria, portanto, designando um processo de instabilização das bases de legitimidade dos responsáveis pelas políticas urbanas, aos quais se podem reprovar, por um lado, a incapacidade de imprimir eficiência na administração dos recursos públicos ou, por outro, a indisposição para democratizar o acesso aos serviços urbanos (ACSELRAD, 2009).

Para Acselrad, a erosão da legitimidade das políticas urbanas pode fundar-se, assim, na insuficiente adesão à racionalidade econômica, causa suposta do desperdício da base de recursos ou, alternativamente, na ausência de priorização de mecanismos distributivos do acesso a tais serviços.

\section{A atuação do PAC em Belém}

O PAC, lançado em 28 de janeiro de 2007, é um programa do governo federal brasileiro que engloba um conjunto de políticas econômicas anticíclicas e que tem como objetivo acelerar o crescimento econômico do Brasil, sendo uma de suas prioridades o investimento em infraestrutura, em áreas como saneamento, habitação, transporte, energia e recursos hídricos, entre outros (AVELAR et. al, 2013).

As medidas que compõem o Programa foram divididas em cinco blocos: investimentos em infraestrutura; estímulo ao crédito e ao financiamento; melhoria do ambiente de investimento; desoneração e aperfeiçoamento do Sistema Tributário Nacional e; ajustes fiscais em longo prazo. Os investimentos no bloco de infraestrutura abrangem três áreas: energética: com os setores de petróleo, combustíveis renováveis, gás natural e energia elétrica; social e urbana: com os setores de habitação, saneamento, transporte urbano, recursos hídricos e o programa Luz para Todos e Logística: com os setores rodoviário, ferroviário, portuário, hidroviário e aeroportuário.

O PAC possui grande relevância no contexto da chamada Nova Política Habitacional brasileira implementada a partir de meados dos anos 2000, pois seus projetos habitacionais também se caracterizaram pela atenção à faixa de até três salários 
mínimos e, pelo fato de ter incorporado projetos do Fundo Nacional da Habitação de Interesse Social (FNHIS), contratados ou em execução, quando de seu advento.

A seleção de ações para a geração do PAC nos municípios apresentou um recorte populacional que abrangia áreas metropolitanas e municípios com população maior que 150 mil habitantes, restringindo, assim, o acesso aos recursos a algumas poucas cidades paraenses, entre elas, Belém.

As demandas por habitação atendidas pelo PAC em Belém foram principalmente as mais antigas, associadas aos graves problemas de saneamento do município e caminharam a passos lentos, não apenas no tocante aos projetos habitacionais, mas principalmente por problemas estruturais em relação à gestão, no que se refere ao repasse de recursos, cumprimento de prazos estipulados e demora na licitação de serviços, entre outros.

As obras desenvolvidas com recursos do PAC na Região Metropolitana de Belém (RMB) são predominantemente voltadas para o setor de infraestrutura urbana, nas modalidades PAC - Urbanização de Assentamentos Precários e PAC - Saneamento Integrado, obras que integram ações de saneamento, habitação, urbanização, bem como regularização fundiária das áreas de intervenção e objetivam a promoção de soluções voltadas à melhoria das condições de habitabilidade e salubridade ambiental em áreas já ocupadas (AVELAR, 2013).

\section{A Comunidade Taboquinha}

A ocupação da área da Comunidade Cubatão se constituiu ao longo dos últimos quarenta anos por contingentes de população de baixa renda em função do agravamento do processo de urbanização, onde cada vez mais famílias se deslocaram do interior do estado para a capital, em busca de oportunidades de melhoria de vida. A Comunidade repetiu uma forma de consolidação muito comum nas últimas décadas em outras áreas de Belém, baseada no adensamento das periferias imediatas aos centros e sub-centros urbanos, principalmente nas áreas alagadas ou alagáveis próximas aos centros de emprego, áreas de "baixada", por estarem situadas abaixo da cota topográfica mais baixa.

Diante dos dados apresentados e de estudos feitos pelo IBGE, o conjunto de setores censitários que englobam a área da Comunidade Taboquinha era classificado como um aglomerado subnormal (IBGE, 2011). Embora as densidades populacionais por setor censitário (que no caso em estudo correspondiam às quadras) são relativamente baixas e indicavam preliminarmente que os problemas existentes na Comunidade 
Taboquinha ocorriam devido à ausência de medidas de proteção ambiental e soluções habitacionais para as famílias que residiam na calha dos cursos d'água, o que foi considerado como justificativa para a sua inclusão no PAC. A Fotografia 01, a seguir, destaca um trecho de ocupação das margens do Igarapé:

Figura 1 - Igarapé Tabocal: pequeno curso de rio antropizado com margens repletas de

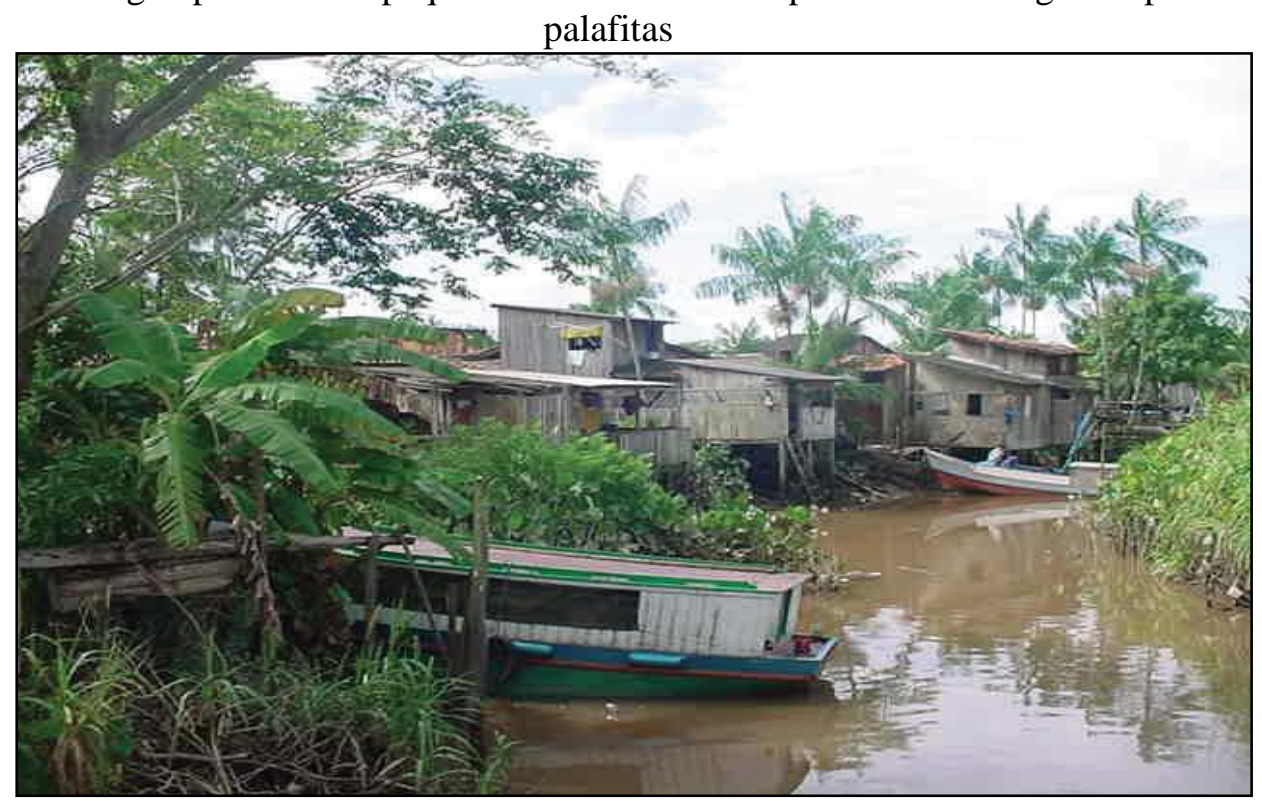

Fonte: PARÁ, 2010.

A inexistência de sistema de drenagem e de rede de esgoto sanitário, na Comunidade, daria lugar a um sistema de drenagem constituído por valas a céu aberto que carreavam todo tipo de águas servidas e poluídas, além de dejetos, os quais, lançados diretamente no leito do igarapé, constituíam permanente agressão ao meio ambiente. Além disso, parte das casas eram palafitas, construídas com madeira branca e se apresentavam em precárias condições de habitabilidade, interligadas através de um sistema de passarelas ou "estivas"” de madeira, sem qualquer proteção lateral ou guardacorpo. O Mapa 01, a seguir, localiza área de intervenção e seu entorno.

\footnotetext{
${ }^{2}$ Lastro feito para passagem sobre alagadiço, com varas ou troncos atravessados, com ou sem amarrilho. Denominação local para pontes de madeira que fazem o papel de calçadas, que se configuram em um tipo de via de penetração, ainda que precária.
} 
Mapa 1 - Polígono de intervenção do PAC Taboquinha

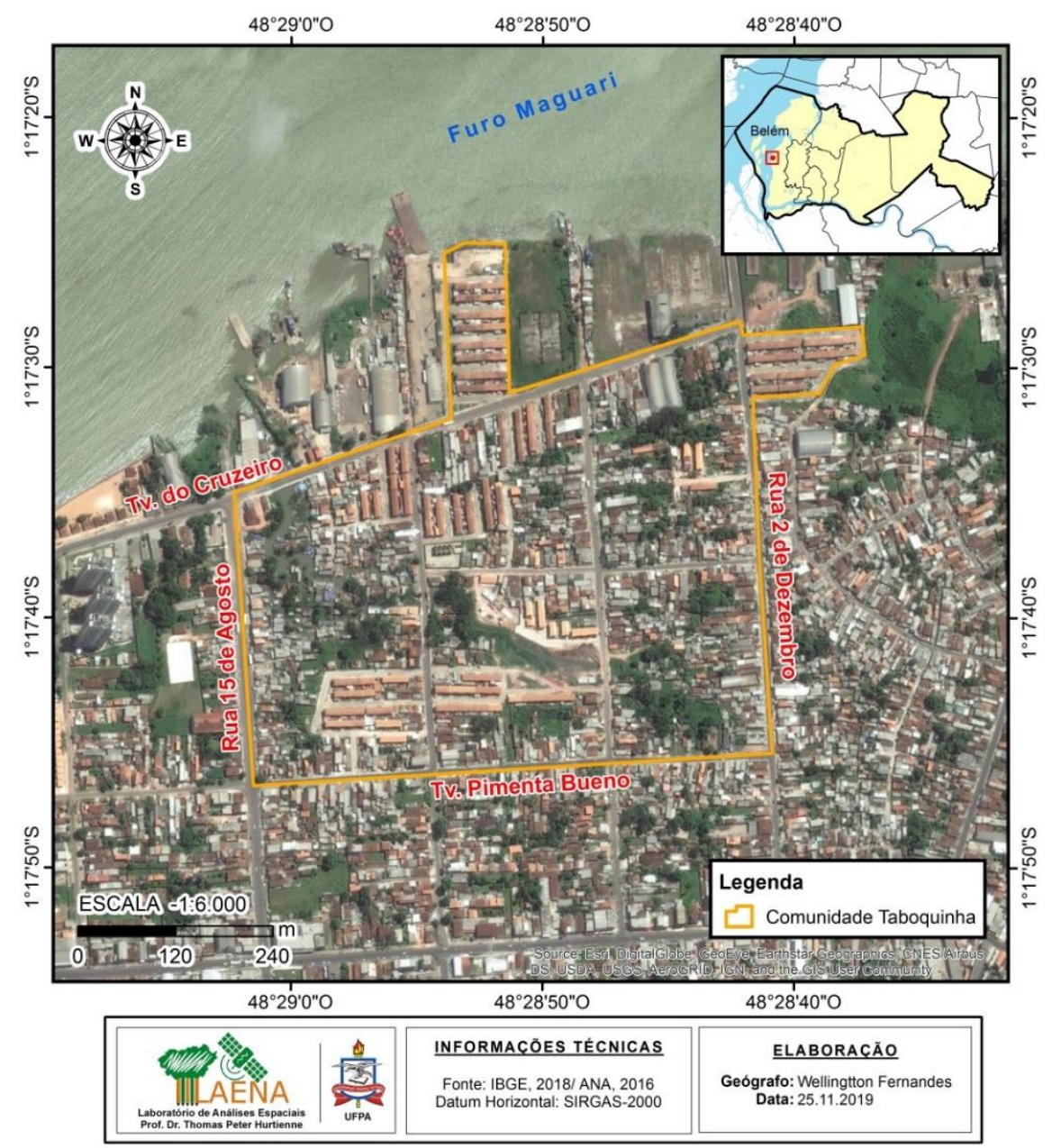

Fonte: IBGE, 2018/ANA, 2016. Elaboração Wellington Fernandes,

\section{LAENA/UFPA.}

A Comunidade vem passando, desde 2008, por um processo de urbanização oriundo do PAC no eixo UAP, as etapas de melhorias urbanísticas e provisão habitacional já foram concluídas, embora falte concluir parte das ações de saneamento integrado. A intervenção teve contrapartida estadual, como órgão executor a Companhia Executiva de Habitação do Estado do Pará (COHAB-PA) e órgão fiscalizador a Caixa Econômica Federal (CEF). As ações previstas para a área envolviam obras integradas de regularização fundiária, serviços de infraestrutura básica (sistema de drenagem, rede de distribuição de água, sistema de esgoto sanitário, sistema viário, terraplenagem, pavimentação, arborização e preservação ambiental), erradicação das palafitas, produção 
de moradia para atender às famílias remanejadas e trabalho técnico social em parceria com o Movimento Nacional de Luta pela Moradia (MNLM) (PARÁ, 2011).

A urbanização da Comunidade Taboquinha contemplou a remoção de famílias das margens do igarapé Tabocal, a reformulação das malhas urbana e viária, a dotação de infraestrutura pública básica (água, luz, esgoto, drenagem) e o reassentamento das famílias impactadas em novas unidades habitacionais dentro da poligonal de intervenção. A manutenção da APP do igarapé Taboquinha vegetada, em contraposição ao modelo de canalizações e concretagens, foi premissa do projeto e a partir dela foram desenvolvidas as soluções urbanas e sanitárias.

Inicialmente, de acordo com os dados do levantamento socioeconômico, fornecido pela executora do projeto, teria como missão beneficiar 1.862 famílias sendo de grande impacto por envolver uma alta quantidade de remoção, precisamente 1.014 imóveis seriam atingidos diretamente com necessidade de remanejamento (PARÁ, 2007). A provisão habitacional foi de construção de 66 unidades habitacionais térreas com área de $39 \mathrm{~m}^{2}$ contendo dois quartos, banheiro, sala/cozinha; melhoria de 100 unidades habitacionais de acordo com a necessidade encontrada em cada uma; e construção de 912 unidades habitacionais tipo sobrado com área de 43,62 $\mathrm{m}^{2}$ distribuídos em sala/cozinha, banheiro e dois quartos, e ainda contém uma área de quintal. A Figura 2 destaca os blocos habitacionais multifamiliares Mestre Cardoso, unidades habitacionais do Projeto Taboquinha.

Figura 2 - PROJETO TABOQUINHA: blocos multifamiliares do Conjunto Mestre Cardoso.

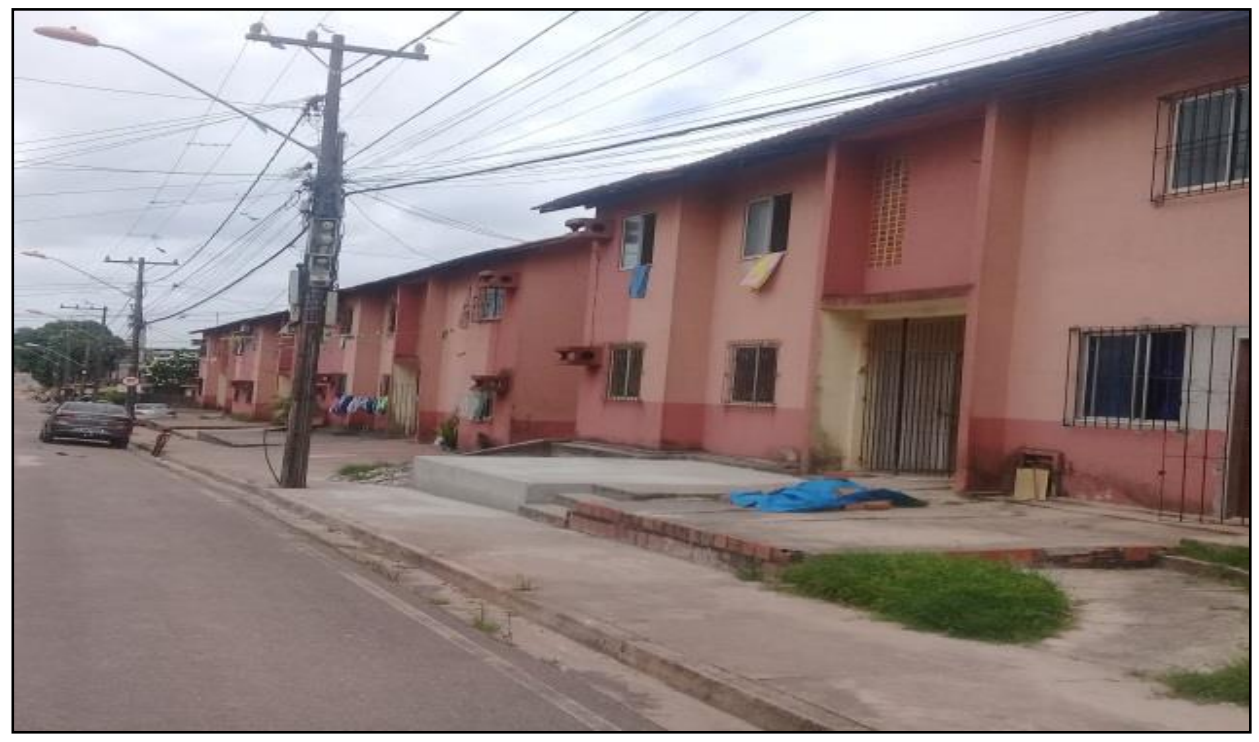

Fonte: Castro (2018) 
O PTTS do Projeto Taboquinha procurou abarcar uma grande quantidade de temas que vão desde o saneamento, até cultura, tentando realizar uma abordagem integrada, sob o pano de fundo da melhoria da qualidade de vida da população beneficiária, eliminação da precariedade física e das condições subumanas de moradia.

$\mathrm{Na}$ intenção de contribuirmos para o combate desta situação, apresentamos a presente proposta que está voltada à erradicação de palafitas na área do TABOQUINHA, onde de forma integrada e com a participação do beneficiário, serão desenvolvidas ações nas áreas, de saneamento, meio ambiente, habitação, educação, trabalho/renda, saúde, segurança, esporte, lazer e cultura. Pretendemos a partir da intervenção proposta contribuir para a promoção de mudanças na realidade atual, onde as famílias estão sobrevivendo em condições subhumanas, localizadas em áreas insalubres e inadequadas para moradia. A legalização da posse do lote urbano será um dos objetivos deste trabalho, intervindo em uma realidade aonde, praticamente, toda a ocupação do solo vem sendo efetuada de maneira irregular e desordenada (PARÁ, 2007, p.8).

Segundo o PTTS, o Projeto de Urbanização da Comunidade Taboquinha seria caracterizado como "uma implementação de prática de gestão ambiental”, numa área de, aproximadamente, $175.000 \mathrm{~m}^{2}$ de influência do Igarapé e seu entorno e incluía: urbanização/sistema viário; sistema de abastecimento de água; drenagem pluvial; esgotamento sanitário; rede de distribuição elétrica; rede de iluminação pública; construção de equipamentos comunitários como: quiosques (para jogos, artesanatos e lanchonete), concha acústica e anfiteatro; áreas destinadas para a construção de quadra polivalente e equipamento escolar; intervenção na área de proteção ambiental, com recuperação da área degradada às margens do Igarapé e remanejamento de famílias lá residentes; atuação na área habitacional com construção (casas novas com as seguintes características: construção em alvenaria de 39,00 m², com sala e cozinha, 2 quartos, circulação e banheiro), ampliação e melhoria de habitações; regularização fundiária.

Nas entrevistas com os agentes responsáveis pela elaboração e execução do Projeto foi destacado também o caráter inédito que trouxe o PAC em relação à destinação de aporte financeiro exclusivamente direcionado ao trabalho técnico social de forma a complementar a mudança das famílias para os conjuntos, o que também exprime a sustentabilidade de forma econômica. Conforme T1 e T2 destacam:

Não podemos falar mal do PAC. Pela primeira vez na história houve recurso exclusivo para um trabalho social, um trabalho que vem somar ao que o projeto físico elabora, de certo modo. No caso do Taboquinha, a mudança foi muito grande porque os locais onde as pessoas moravam era precário e a mudança para os blocos foi um grande avanço para as famílias, embora saibamos que ainda há muito o que melhorar nessa 
dinâmica tanto em relação ao projeto das unidades, quanto nas condições de vida das famílias.

O PAC foi um laboratório incrível para nós [...] a amarração que as normativas têm na questão ambiental é muito importante (T2).

Nas entrevistas com os sujeitos foi perceptível que estes viram a mudança para os conjuntos como positiva, sendo as unidades vistas como adequadas em comparação à ocupação onde residiam.

Nos termos do PTTS, a sustentabilidade reside em, além de "acabar com as palafitas na área do TABOQUINHA [...]”, auxiliando na “[...] promoção de mudanças na realidade atual [...]", sem, no entanto, alterar o quadro de pobreza material estrutural das famílias, os inserindo naquilo que Lefebvre chama de espaço abstrato, numa tendência de continuação da atuação do Estado, via PAC, na reprodução de espaços para habitação contraditórios, como reprodução de espaços-mercadorias, impondo controle social sobre as famílias a partir do remanejamento e da padronização monótona da tipologia que não tem relação com o entorno e com a própria cidade, no que Lefebvre (1973, p.67) chama de "periferias desurbanizadas, mas dependentes de cidade".

\section{Análise das categorias lazer e trabalho}

Apesar de as respostas, de modo geral, mostrarem a melhoria na estrutura como elemento positivo para as famílias, o lazer aparece como lacuna não preenchida pelo projeto, ou minimamente preenchida, uma vez que apenas um dos conjuntos habitacionais do projeto foi contemplado com equipamentos urbanos dedicados ao lazer da comunidade, é importante o fato da diferenciação sempre apontada entre o "antes" e o “depois” da inserção das famílias nos conjuntos do projeto:

Olha... Pra mim, que era acostumada desde pequena a brincar na rua, apesar de ser ponte (na Ocupação), aqui tá pior o lazer. Apesar de ser ponte, quando a gente era menor todo mundo se conhecia. Aqui não... Muita gente já foi embora, outras pessoas chegaram e a gente não conhece, né? (E2)

Percebe-se claramente na fala do entrevistado que houve perda de laços entre os membros da comunidade a partir das mudanças estabelecidas, o que se expressa na condição atual de lazer, onde embora haja melhores condições físicas, os aspectos ligados ao companheirismo, ao afeto presentes no grupo são levados em consideração para avaliar a perda sofrida. Outros elementos importantes foram observados, principalmente no que se refere a pouca infraestrutura de lazer possibilitada, como frisou E8. Por outro lado, 
houve, segundo E6, uma mudança de perfil etário na comunidade empiricamente demonstrado pelo entrevistado:

Aqui (Conjunto Mestre Cardoso) não foi construído nada... No Verequete (Conjunto) teve uma quadra (de esportes), mas já acabou, tá destruída... (E8)

Na opinião dos agentes envolvidos, a incapacidade de atenção e efetivação dos espaços de lazer em cada conjunto se deu pela falta de atualização dos valores orçados inicialmente nos projetos, fato que limitou a possibilidade de conclusão das obras, dando primazia à moradia em relação a outros elementos, também relevantes no processo de transição entre espaços.

Poucas respostas analisam o lazer a uma perspectiva de descanso ou de tempo livre em função do trabalho diário. O lazer é visto pelos responsáveis pelos domicílios, geralmente, como um aspecto especificamente desejável para crianças e jovens desfrutarem. As associações à vida material dos responsáveis pelos domicílios estão relacionadas ao final de semana, aos encontros com amigos, às festas e ao consumo. $\mathrm{O}$ processo de transição entre o espaço precário da ocupação ao novo espaço urbanizado conseguiu diminuir riscos de doenças, contato com a água poluída do Igarapé Tabocal, no entanto, também desarticulou relações entre famílias e pessoas, laços de vizinhança e proximidades.

Os agentes entrevistados dizem compreender que a efetivação da intervenção quanto ao lazer é aquém do esperado e do necessário à Comunidade, entretanto, frisam que as contingências tiveram como causa problemas de repasse financeiro à executora, problemas relacionados à gestão e redefinição de prioridades. As opiniões de agentes e sujeitos convergem no entendimento da primazia dada às unidades habitacionais em relação a qualquer outro elemento do projeto, consideradas prioridades por conta da necessidade de remoção das famílias. O papel do PTTS em relação ao lazer foi muito mais direcionado ao estabelecimento de temas afins, como oficinas sobre relações de vizinhança (embora no processo de remoção, essas relações não tenham sido respeitadas plenamente, pois houve sorteio entre os sujeitos para definição de qual família ficaria em determinada unidade), meio ambiente e trabalho, em um sentido de contato entre pessoas e famílias, que propriamente ações de lazer de modo objetivo.

Quanto ao trabalho, as ações propostas pelo PTTS buscaram ter relevância dentro de um contexto de baixa qualificação percebida no perfil da população, embora não estejam conectadas a ele claramente. O projeto não destinou, por exemplo, qualquer 
atividade aos trabalhadores da pesca, considerados na análise do perfil socioeconômico como parcela significativa. Mesmo que tendo uma leitura sobre sustentabilidade mais próxima ao aspecto socioeconômico, o Projeto não conseguiu fazer uma interpretação das necessidades da comunidade, neste aspecto. Desprezou-se, assim, a vivência da população e uma importante expressão relacionada à sua base material. Assim como em Acselrad (2009), a noção de sustentabilidade apresentada no bojo do projeto e em sua execução, constitui apenas parte de um esforço de configurar um novo modo de regulação urbana capaz de integrar duravelmente na dinâmica reprodutiva a própria desigualdade constitutiva da cidade, sem alterar mais que o lugar de habitação, incapaz de intervir diretamente nas causas da desigualdade, embora sinalize enfatizar a preocupação com o aspecto socioeconômico.

Para evidenciar informações sobre a categoria trabalho, as entrevistas foram conduzidas de forma a identificar rupturas e permanências nas condições de trabalho dos chefes de famílias a partir do processo de mudança da ocupação para os conjuntos habitacionais do Projeto Taboquinha, entendendo que este processo tende a refletir na organização familiar e sua subsistência material, fundamental para a permanência das famílias nos conjuntos e a sua reprodução social.

Quanto à interveniência do processo de mudança para as condições de trabalho e seu desenvolvimento, há entre entrevistados a predominância do entendimento de que a mudança de espaço de habitação não teve influência direta em relação ao tema trabalho, embora sejam significativas algumas mudanças para parcela que possuía ocupações autônomas e prestadores de serviço. E6 frisou que seus clientes permaneceram os mesmos, mesmo depois da mudança para o Conjunto Mestre Cardoso, "[...] meus clientes são os mesmos. Eu trabalho com costura”. Entretanto, no que diz respeito às condições para execução de seu trabalho, uma mudança significativa ocorreu, mudança comum a todos os sujeitos e que se tornou uma queixa presente em praticamente todas as entrevistas realizadas nos conjuntos do Projeto Taboquinha: o aumento do valor da conta de energia elétrica.

E13 correlaciona a mudança de residência ao trabalho por ele desenvolvido, que, segundo o entrevistado, foi prejudicado pelo tamanho da unidade habitacional, aquém do tamanho da sua residência anterior na comunidade Taboquinha, além de ter recebido a promessa de ser contemplado com um ponto comercial no Conjunto, o que não ocorreu:

Meu trabalho dependia da minha casa antiga, que era bem maior. Eu trabalhava embaixo e morava em cima. Eu era cabeleireiro, antes de 
sofrer um AVC e, durante as obras, prometeram que haveria um ponto pra trabalhar... Não teve nem ponto de agulha, quanto mais pra trabalho... (E13)

Outro elemento muito importante para a análise do tema trabalho é a relação com a precariedade no abastecimento de água, que, no caso do E13 serve de insumo essencial para o desenvolvimento de sua ocupação:

As pessoas enchem a boca pra falar que moram em apartamento... Apartamento nada! É um em cima do outro... Se me perguntar quantas vezes a caixa d'água encheu, eu vou dizer umas duas ou três vezes em oito anos... Como eu poderia trabalhar assim? Não tem água. (B13)

Houve desconexão entre as demandas apontadas pelo estudo socioeconômico que fundamentou o PTTS e as atividades propostas, que apesar de importantes, foram vistas como "rápidas" e descontínuas pelos entrevistados:

No início, teve muitos cursos: de pedreiro, customização de roupas e outros, mas depois não teve continuidade. (E8)

As entrevistas ratificaram o entendimento de que não houve correlação entre o planejamento pensado e a execução do Projeto que optou por atividades que não estavam relacionadas à base material das famílias remanejadas e reassentadas nos conjuntos, fato que descontextualizou a própria referência de sustentabilidade inserida no projeto.

A sustentabilidade apareceu como elemento chave entre aspectos físicos e sociais no PTTS do Projeto Taboquinha, onde as estratégias pensadas pelos elaboradores visaram contribuir com ações destinadas à geração de ocupação e renda das famílias remanejadas para os conjuntos habitacionais construídos, conforme um dos objetivos propostos:

Realizar oficinas e/ou cursos de capacitação e qualificação profissional, proporcionando acesso das famílias a atividades de ocupação e renda, que leve ao desenvolvimento econômico-financeiro que venha a contribuir para a sua fixação na área e a sustentabilidade das obras e serviços implantados (PARÁ, 2007, p.10). Grifo nosso.

A sustentabilidade é vista como objetivo a ser atingido para a manutenção e a fixação dos sujeitos aos conjuntos habitacionais, primeiramente, numa dimensão econômica, mas com sentido de tornar esses sujeitos plenamente adaptados ao novo ambiente de moradia, numa clara perspectiva social, onde a melhoria da qualidade de vida das famílias apareceu como o objetivo final. Esta ideia tentou compatibilizar a necessidade de superação do quadro socioambiental problemático no espaço intraurbano com o desenvolvimento de uma política anticíclica de geração de emprego e renda, uma vez que também procurou aproveitar a mão de obra local nas próprias obras executadas 
- ação contida na normativa de execução dos projetos - e, ao mesmo tempo, possibilitar alguma qualificação para a população beneficiária por meio dos cursos e oficinas ofertadas pelo PTTS.

Pretendemos a partir da intervenção proposta, contribuir para a promoção de mudanças na realidade atual, onde as famílias estão sobrevivendo em condições sub-humanas, localizadas em áreas insalubres e inadequadas para moradia (PARÁ, 2007, p. 7-8).

Nas entrevistas com os técnicos do Trabalho Social da COHAB-PA, agentes responsáveis pela execução do PTTS, ratificou-se o entendimento sobre a sustentabilidade como aspecto importante a ser considerado, porém, sempre referente ao viés econômico, e, em primeiro lugar, à geração de ocupação e renda, ainda que de modo superficial, estando distantes quaisquer elementos ambientais. A adaptação das famílias tem primazia em relação às questões culturais ou relação dos sujeitos com o espaço construído:

A perspectiva do trabalho técnico social é possibilitar ações que diminuam o impacto dessa transição (da ocupação ao conjunto habitacional), principalmente no que diz respeito à melhoria da renda $\mathrm{e}$ condições de vida na nova residência. Muitas oficinas de artesanato, de panificação, de corte e costura, por exemplo, foram disponibilizadas para os beneficiários que buscaram nelas uma forma de melhorar sua renda, tudo isso ligado ao perfil socioeconômico que foi identificado [...] desse jeito, as famílias conseguem uma forma de obtenção melhoria da renda que antes não existia (T2).

As estratégias para a utilização dos valores sustentáveis permaneceu distanciado da realidade das famílias. Articulou-se idealmente a sustentabilidade como meta projetual, mas, contrariamente, ratificou-se a ideia de que bastaria a transposição das famílias para os novos conjuntos habitacionais para que a sustentabilidade tivesse êxito, na alegação de a melhoria da "qualidade de vida" fosse alcançada.

\section{CONCLUSÕES}

O conceito de sustentabilidade urbana pode ser considerado um aglutinador de perspectivas ambientais e sociais na compreensão da cidade e de seus problemas, no entanto, no momento atual de crise do modelo neoliberal de gestão, passa a ser tomado como um discurso amplamente incorporado ao campo do planejamento urbano.

Não é possível pensar nos conjuntos habitacionais periféricos para remanejamento de famílias em situação de vulnerabilidade descolados da realidade e do sistema econômico que o produz e das implicações que essa produção traz consigo. Considerar a estrutura socioeconômica e as carências não apenas advindas dela é indispensável para 
entender como esses espaços habitacionais para os mais pobres são produzidos, como é o caso em estudo.

A pesquisa empírica mostrou como a moradia pós-remoção nos conjuntos do Projeto Taboquinha inclui desde a desconsideração das características do perfil da população beneficiária, quanto ao trabalho no PTTS, à estrutura precária de lazer, dos problemas com o sistema de transporte público à baixa qualidade dos serviços de coleta de lixo, da carência de instrução formal via acesso às escolas públicas à violência urbana. Além disso, o conjunto habitacional com espacialidade heterônoma e seu caráter anistórico exercem uma força desmobilizadora sobre a população beneficiária que nele vive, dificultando a formação de laços sociais e de vizinhança e apropriações afetivas e simbólicas com o lugar. Quando muito, as estruturas físicas dos conjuntos permitem, para alguns moradores, a construção de pequenas intervenções espaciais, que estão, contudo, no domínio individual. O tipo de estrutura social que é construída a partir da estrutura física dos grandes conjuntos não aponta para a autonomia coletiva, para a emancipação nos termos lefebvrianos. Ao contrário, reforça uma tendência atual das periferias pobres nas grandes cidades, o que chamamos aqui (in) sustentabilidade, isto é, de sobrevalorização da vida individual e subvalorização da vida coletiva, social e política, numa espécie de recusa ao direito à cidade.

O Programa impôs o tipo de espaço de moradia, tipo de espaço de lazer, tipo de consumo. São espaços abstratos que se contrapõem a espaços sociais (do comércio, das feiras, dos campos de futebol, dos ambulantes). Cria-se um espaço que, entre outros problemas, valoriza o quantitativo, o regulado, sem valor de uso, o espaço-produto, como fotocópia de um espaço-mercadoria.

A sustentabilidade descrita no PTTS do Projeto Taboquinha mostrou-se discursiva e deslocada da realidade atual das famílias na efetivação do projeto e no reassentamento, pois as ações basearam-se exclusivamente no aspecto econômico, sem nenhum nexo com a vida material dos beneficiários. Embora o acesso à casa própria seja valorizado e as condições de habitação sejam apontados como melhores em relação à precariedade da ocupação irregular e vulnerável habitada anteriormente, na categoria lazer permaneceu uma lacuna não preenchida que denota, além da desconsideração da necessidade de espaços e relações, a reprodução de uma lógica pautada na homogeneização, na monotonia e sem conexão com as vivências da população atendida. Na categoria trabalho, embora as condições de habitabilidade tenham melhorado após o reassentamento, as 
ações do PTTS não possuem qualquer relação com as vivências da população trabalhadora reassentada.

\section{REFERÊNCIAS}

ACSELRAD, H. Sentidos da sustentabilidade urbana. In: ACSELRAD, H. (Org.). A duração das cidades: sustentabilidade e risco nas políticas urbanas. 2.ed. Rio de Janeiro: Lamparina, 2009. p. 43-70.

Discursos da Sustentabilidade. Revista Brasileira de Estudos Urbanos e Regionais, número 1, p. 79-90, 1999.

AVELAR, W.M; SOUZA, E.S; PONTE, J.P.X; MELO, A.C.C. O Programa de Aceleração do Crescimento e a urbanização de favelas na Região Metropolitana de Belém - PA. Anais dos Congressos da ANPUR. 2013.

COMPANHIA EXECUTIVA DE HABITAÇÃO DO ESTADO DO PARÁ.

Comunidade Taboquinha. Projeto oficial licitado Belém: COHAB-PA, novembro, 2007. CD-ROM. [Projeto executivo de engenharia e urbanismo, desenhos técnicos digitais].

GOTTDIENER, M. A produção social do espaço urbano. São Paulo: Edusp, 2010.

INSTITUTO BRASILEIRO DE GEOGRAFIA E ESTATÍSTICA - IBGE. Municípios. Disponível em http://ibge.gov.br. Acesso em 10 de setembro de 2020.

Aglomerados Subnormais, Informações Territoriais. Primeiros resultados. Rio de Janeiro, 2012.

LEFEBVRE, H. A Reprodução das Relações de Produção. Tradução: António Ribeiro e M. do Amaral. Porto: Publicações Escorpião - Cadernos O Homem e a Sociedade, 1973.

LEFF, E. Ecologia, capital e cultura: a territorialização da racionalidade ambiental. Petrópolis: Editora Vozes, 2009.

PARÁ. Companhia Executiva de Habitação do Pará. Projeto de Trabalho Técnico Social do Projeto PAC Taboquinha. Belém: COHAB, 2007. Inédito.

Plano de Remanejamento e Reassentamento de Famílias e Atividades

Econômicas: Comunidade da Taboquinha. Belém: [s.n.], 2010.

PARÁ. Companhia Executiva de Habitação do Pará. Balanço das Ações de 2012. Slides Ppt. Belém: COHAB, 2011.

PRADO, A. L. Desenvolvimento urbano sustentável: de paradigma a mito. Revista Oculum. Número 12, v. 1, p.83-97, 2015. 
SOUZA, M.L. O desafio metropolitano: um estudo sobre a problemática socio-espacial nas metrópoles brasileiras. Rio de Janeiro: Bertrand Brasil, 2009.

Recebido em: 20/11/2021

Aprovado em: 10/12/2021

Publicado em: 14/12/2021 